UCRL-JC-124033

PREPRINT

CONF $-960543-13$

\title{
A Novel Method for Diagnosing the Growth of Subresolution-Scale Perturbations
}

K. S. Budil, B. A. Remington, T. S. Perry, A. M. Rubenchik, M. Berning, T. A. Peyser, H. Louis, T. Demiris, and R. Wallace
PECEIVED

MAY 301996

OSTI

This paper was prepared for submittal to the 11th Topical Conference on High-Temperature Plasma Diagnostics Monterey, California May 12-16, 1996

May 3, 1996

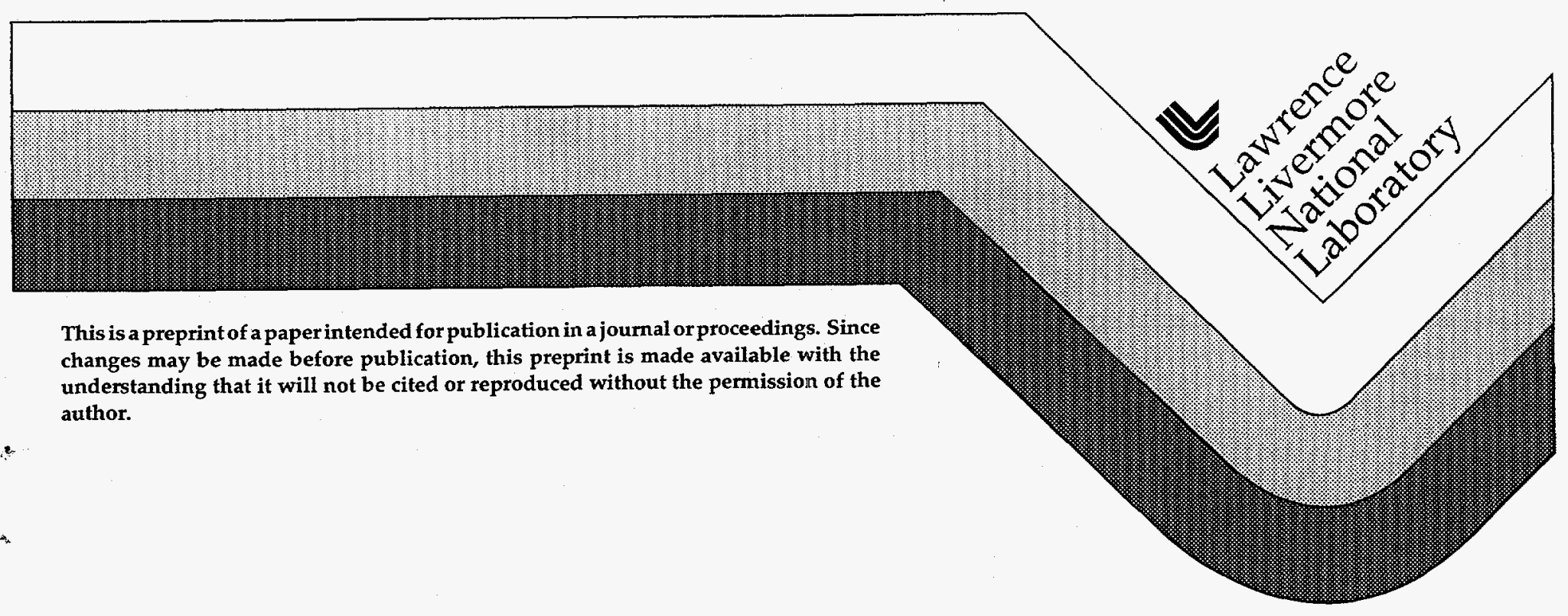

This is a preprint of a paper intended for publication in a journal or proceedings. Since changes may be made before publication, this preprint is made available with the understanding that it will not be cited or reproduced without the permission of the author. 
This document was prepared as an account of work sponsored by an agency of the United States Government. Neither the United States Government nor the University of California nor any of their employees, makes any warranty, express or implied, or assumes any legal liability or responsibility for the accuracy, completeness, or usefulness of any information, apparatus, product, or process disclosed, or represents that its use would not infringe privately owned rights. Reference herein to any specific commercial product, process, or service by trade name, trademark, manufacturer, or otherwise, does not necessarily constitute or imply its endorsement, recommendation, or favoring by the United States Government or the University of California. The views and opinions of authors expressed herein do not necessarily state or reflect those of the United States Government or

the University of California, and shall not be used for advertising or product endorsement purposes. 


\section{DISCLAMIER}

Portions of this document may be illegible in electronic image products. Images are produced from the best available original document. 


\title{
A novel method for diagnosing the growth of subresolution-scale perturbations
}

K. S. Budil, B. A. Remington, T. S. Perry, A. M. Rubenchik, M. Berning, T. A. Peyser, H. Louis, T. Demiris, and R. Wallace Lawrence Livermore National Laboratory P. O. Box 808, Livermore, CA 94550

\begin{abstract}
We have demonstrated a technique for diagnosing the growth of subresolution-scale perturbations by the appearance of longer-wavelength, coupled modes once the growth has proceeded into the nonlinear regime. Comparison of the growth rate of this larger scale feature with numerical simulations can then be used to infer the growth rates of the initial perturbations. This experiment was conceived as an analog of large-scale computer simulations where the large eddy approximation is applied: There a subgrid-scale model is used to represent the effects of small scales on largescale motion, which is directly numerically simulated.
\end{abstract}

Hydrodynamic instabilities have been studied extensively due to their presence in numerous physical systems. The Rayleigh-Taylor (RT) instability is particularly important to the process of inertial confinement fusion (ICF). In direct-drive schemes imprinting (and subsequent growth) of the initial laser intensity profile can cause implosion nonuniformities while in indirectdrive a reasonably uniform x-ray drive is used to implode the capsule but surface imperfections can seed instability growth. Large growth of 
perturbations on the outer surface of the capsule could cause the pusher to break up before the implosion has reached peak compression. Alternatively, perturbations which feed-through from the capsule surface to the pusher-fuel interface will be unstable and grow during deceleration and stagnation, degrading capsule performance.

Another field replete with examples of hydrodynamic instabilities is astrophysics, where star models rely heavily on correctly. accounting for the effects of turbulent mixing. Such a system spans many orders of magnitude in length scale which precludes direct numerical simulation. The number of grid points required to account for both large and small scale structures is prohibitive. One technique which is adopted to model such systems is the large eddy simulation (LES), where small structures are modeled theoretically with a subgrid-scale model and the largest scales are directly numerically simulated. ${ }^{1}$

We have conceived of an experiment which applies the same logic to the study of the evolution of subresolution-scale perturbations at an RTunstable interface. Here an initial perturbation consisting of two wavelengths superposed in phase, both smaller than the experimental resolution $(\sim 8 \mu \mathrm{m}$ at 12 times magnification), is imposed at an embedded interface where very short wavelengths $(\lambda \sim 10 \mu \mathrm{m})$ have previously been demonstrated to grow strongly. ${ }^{2}$ The initial perturbation cannot be directly probed, but if the growth proceeds into the nonlinear regime the two initial modes will couple producing structures at the beat frequencies. The longer wavelength beat mode is well within the experimental resolution and its growth rate can be measured. By comparison with simulations, the growth rate of the two initial modes can then be inferred. 
The experimental configuration is shown in Figure 1. A $750 \mu \mathrm{m}$ diameter planar package is affixed across a hole in a $3 \mathrm{~mm}$ long by $1.6 \mathrm{~mm}$ diameter gold cylindrical hohlraum. Eight of the ten Nova beams at $.351 \mu \mathrm{m}$ wavelength are used to generate a $4.5 \mathrm{~ns}$ shaped $\mathrm{x}$-ray drive. The remaining two beams at $.528 \mu \mathrm{m}$ are delayed with respect to the drive beams and focused onto an iron backlighter disk to generate $6.7 \mathrm{keV} \mathrm{He}-\alpha \mathrm{x}$-rays to backilluminate the accelerating experimental package. To produce a smooth 700 $\mu \mathrm{m}$ diameter x-ray spot, random phase plates with $5 \mathrm{~mm}$ hexagonal elements are inserted into the backlighter beam lines. Gated $x$-ray images are obtained with a gated pinhole camera, the flexible $x$-ray imager (FXI). ${ }^{3}$

The FXI records 16 images (4 images/strip, 4 striplines) at 12 times magnification of the accelerating foil in flight. The images on a single strip are separated by $\sim 70$ ps and interstrip timing can be adjusted in $100 \mathrm{ps}$ increments. Each image is converted from film density to $\ln ($ exposure) $\propto-$ optical depth $=-\int \rho \kappa d z$, where $\rho$ is the density and $\kappa$ is the opacity.

The planar experimental packages consisted of a $40 \mu \mathrm{m}$ thick brominated plastic ablator $\left(\mathrm{C}_{50} \mathrm{H}_{47} \mathrm{Br} 3, \rho=1.26 \mathrm{~g} / \mathrm{cm}^{3}\right)$ backed by a $15 \mu \mathrm{m}$ thick titanium payload $\left(\rho=1.26 \mathrm{~g} / \mathrm{cm}^{3}\right)$. The targets were manufactured by machining the desired perturbation shape into a copper mandrel which was then coated with Ti by vapor deposition. While the Ti foil was still supported by the mandrel, the back side was faced off to produce the correct thickness. When this process was complete, the $\mathrm{Cu}$ mandrel was chemically etched away. The $\mathrm{CH}(\mathrm{Br})$ layer was then pressed onto the rippled side of the Ti foil. For the experiment discussed here the perturbation consisted of $\lambda=4$ $\mu \mathrm{m}$ and $\lambda=5 \mu \mathrm{m}$ sinusoids with initial amplitude $\eta_{\mathrm{o}}=.3 \mu \mathrm{m}$ superposed in phase, as illustrated in Figure 2. 
The hohlraum radiation drive has been characterized and Figure 3a shows the laser power profile and corresponding radiation temperature evolution. This radiation temperature profile has been used to calculate the trajectory of the back side of the experimental package with the 1-dimensional . radiation-hydrodynamics code HYADES. 4 Figure $3 b$ shows this calculation as well as the predicted acceleration profile at the $\mathrm{CH}(\mathrm{Br})-\mathrm{Ti}$ interface.

First we consider the problem of a single mode perturbation at the embedded interface. In the linear regime, where the amplitude to wavelength scaling $\mathrm{k} \eta$ is small, the growth of the perturbations can be calculated by solving

$$
\partial^{2} \eta_{i} / \partial t^{2}=k_{i} g(t) A(t) \eta_{i}
$$

where $k_{i}$ is the wavenumber, $g(t)$ is the interface acceleration and $A(t)=$ $\left(\rho_{1}-\rho_{2}\right) /\left(\rho_{1}+\rho_{2}\right)$ is the Atwood number. When $k \eta$ is no longer small (typically $k \eta \geq 0.1$ ), the growth enters the nonlinear regime. This is characterized by the appearance of higher harmonics of the initial mode in Fourier space and the shape of the perturbation evolves from sinusoidal to the characteristic "bubble and spike" profile. Here the growth of the fundamental mode slows but the overall growth is not necessarily decreasing. Rather it is being distributed to the higher harmonics of the fundamental mode.

If we now consider the case of interest here where two modes are initially present, once the growth enters the nonlinear regime the modes begin to couple, leading to the appearance of beat modes. A second-order perturbation expansion can be used to derive a relationship for the amplitude of the beat modes yielding 
$\partial^{2} \eta_{i-j} / \partial t^{2}=k_{i-j} g(t) A(t) \eta_{i-j}+2 A(t) k_{i-j}\left\{\left(\partial^{2} \eta_{j} / \partial t^{2}\right) \eta_{i}+\left(\partial \eta_{i} / \partial t\right)\left(\partial \eta_{j} / \partial t\right)\right\}$

Saturation of the growth of the initial modes is taken into account by expressing their amplitude as

$$
\left(1 / \eta_{j}(t)\right)=\left(1 / \eta_{i o}\right)+k_{i}
$$

so that as $\eta_{i o}$ becomes large $\eta_{j}(t) \sim 1 / k_{i}$. This coupling causes a redistribution of the original mode spectrum to longer and shorter wavelengths and impacts the saturation of the individual modes. The initial perturbation wavelengths are below the experimental resolution of the FXI which has a value of the modulation transfer function (MTF) of $10^{-5}$ at $\lambda=5 \mu \mathrm{m}$ compared to .38 at $\lambda=20 \mu \mathrm{m}$ at 12 times magnification with $5 \mu \mathrm{m}$ pinholes. 5 If the $\mathrm{k}=20 \mu \mathrm{m}$ beat mode appears, this will signal that the growth of the 4 and $5 \mu \mathrm{m}$ wavelength initial modes has been driven into the nonlinear regime. Further, by comparison with simulations one can use the growth of the $20 \mu \mathrm{m}$ beat mode to infer the growth of the initial modes.

Figure 4 shows a sample experimental image of the raw data taken at $t$ $=5.5 \mathrm{~ns}$ after the start of the drive pulse. Each image (in $\ln ($ exposure)) is then Fourier analyzed and corrected for the instrument response. Figure $5 \mathrm{a}$ shows an averaged (over approximately one-third of the image) lineout from the data and Figure $5 \mathrm{~b}$ shows the resulting Fourier transform. Here the transform is performed over $120 \mu \mathrm{m}$ so mode 6 corresponds to a feature at 20 $\mu \mathrm{m}$ wavelength. The result of this analysis is the amplitude of the $\mathrm{k}_{-}=20 \mu \mathrm{m}$ beat mode as a function of time and is presented in Figure 6. Overlaid on 
Figure 6 is a calculation of the amplitude of the beat mode, normalized to the data at $4.5 \mathrm{~ns}$.

In conclusion, we have demonstrated a novel technique for the diagnosis of subresolution-scale perturbations by measuring the growth of beat modes which arise when the growth of the initial modes has proceeded into the nonlinear regime and they have begun to couple. The amplitude of the longer wavelength beat mode has been used to infer the growth rate of the initial perturbations. This is an experimental analog of the technique of large eddy simulations wherein small scales are modeled theoretically by subgrid-scale models and large scale features are directly numerically simulated.

The authors wish to acknowledge the expert support S. Alvarez, R. Mazuch, A. Nikitin, D. Hargrove and the technical staff at Nova. This work was performed under the auspices of the U.S. Department of Energy by the Lawrence Livermore National Laboratory under contract number W-7405ENG-48.

\section{References}

1 V. M. Canuto, The Astrophysical Journal 428, 729-752 (1994) ; and references therein.

2 K. S. Budil, B. A. Remington, T. A. Peyser, et al., Physical Review Letters, to be published (1996)

3 K. S. Budil, T. S. Perry, P. M. Bell, et al., Review of Scientific Instruments 67, 485-488 (1996)

4 J. T. Larsen and S. M. Lane, J. Quant. Spect. Rad. Trans. 51, 179 (1994) 
Conference on High-Temperature Plasma Diagnostics, Monterey, CA, (1996).

\section{Figure Captions}

Figure 1: Experimental schematic.

Figure 2: Plot of 4 and $5 \mu \mathrm{m}$ wavelength sinusoids with initial amplitude 0.3 $\mu \mathrm{m}$ along with their sum, the perturbation imposed at the embedded interface in these experiments.

Figure 3: a. Model radiation temperature and laser power for these experiments. b. Acceleration profile at the embedded interface and the trajectory of the rear surface of the Ti payload as calculated with HYADES.

Figure 4: Image of the "raw" data at $t=5.5$ ns after the initiation of the laser drive.

Figure 5: a. Averaged lineout from the data in $\ln (e x p o s u r e)$. b. Fourier spectrum from the lineout where mode 6 corresponds to $\lambda=20 \mu \mathrm{m}$.

Figure 6: Amplitude of the $\lambda=20 \mu \mathrm{m}$ mode in $\ln$ (exposure). The dashed curves are calculations where the thickness of the $\mathrm{CH}(\mathrm{Br})$ ablator has been varied. 


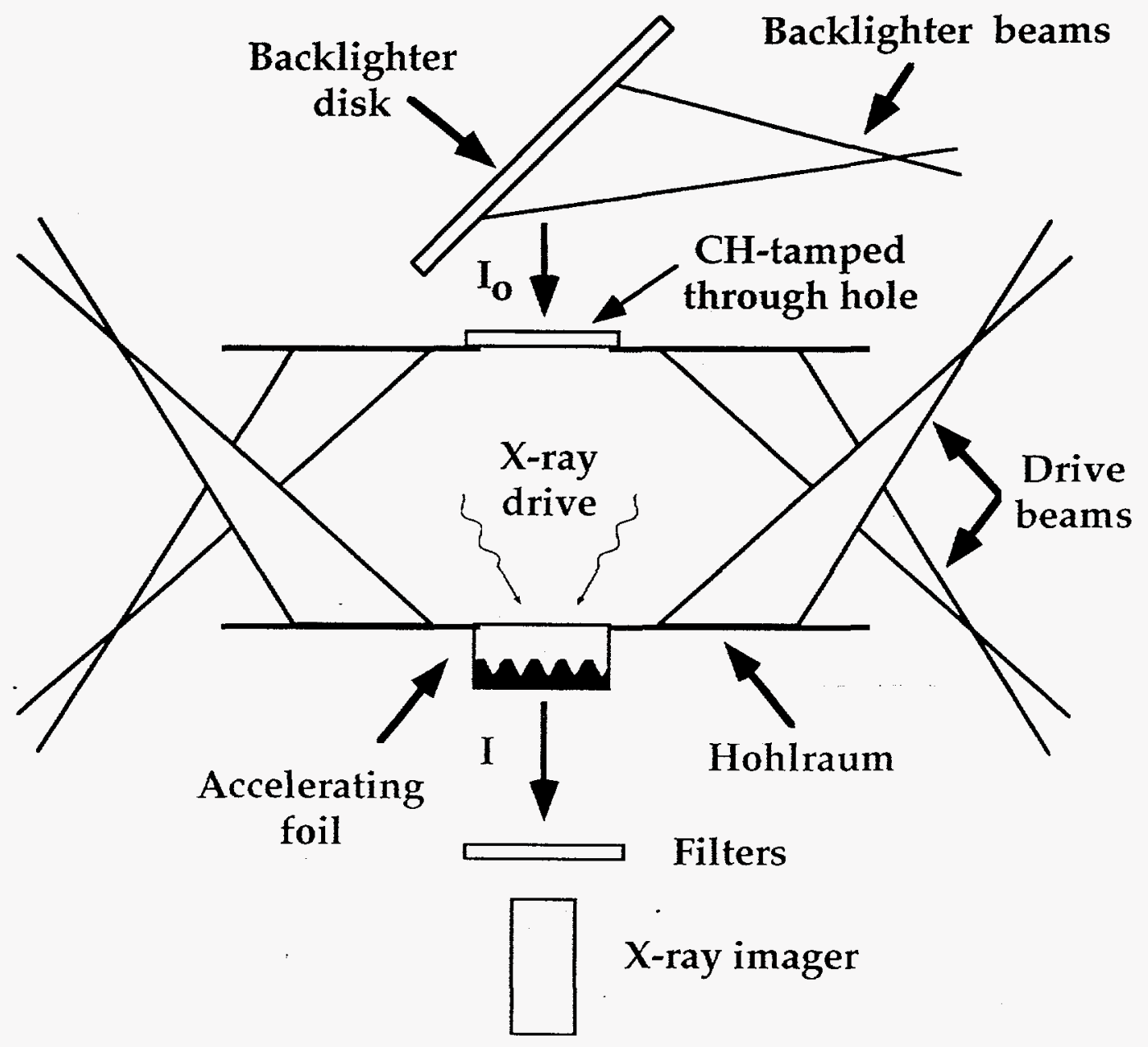

Figure 1 


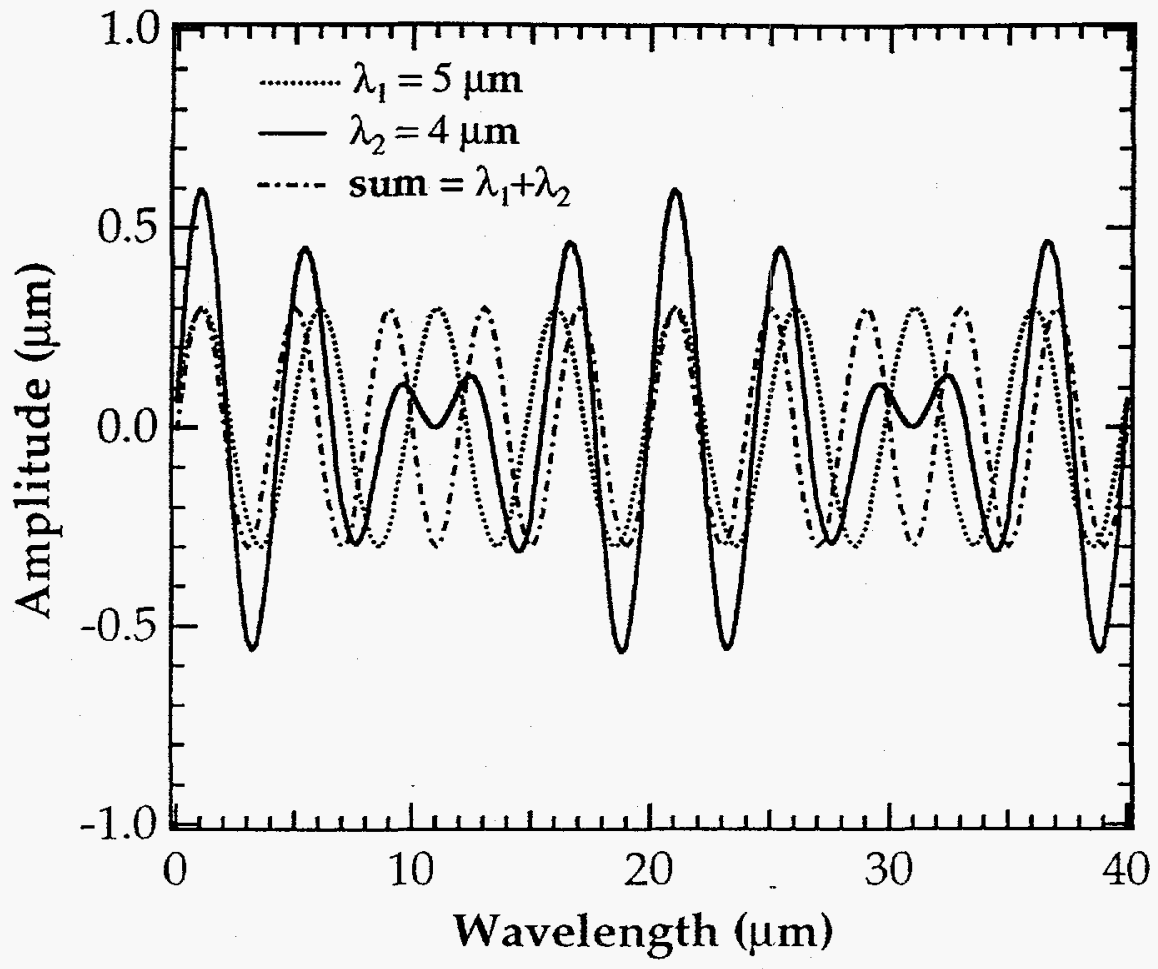

Figure 2 
a.

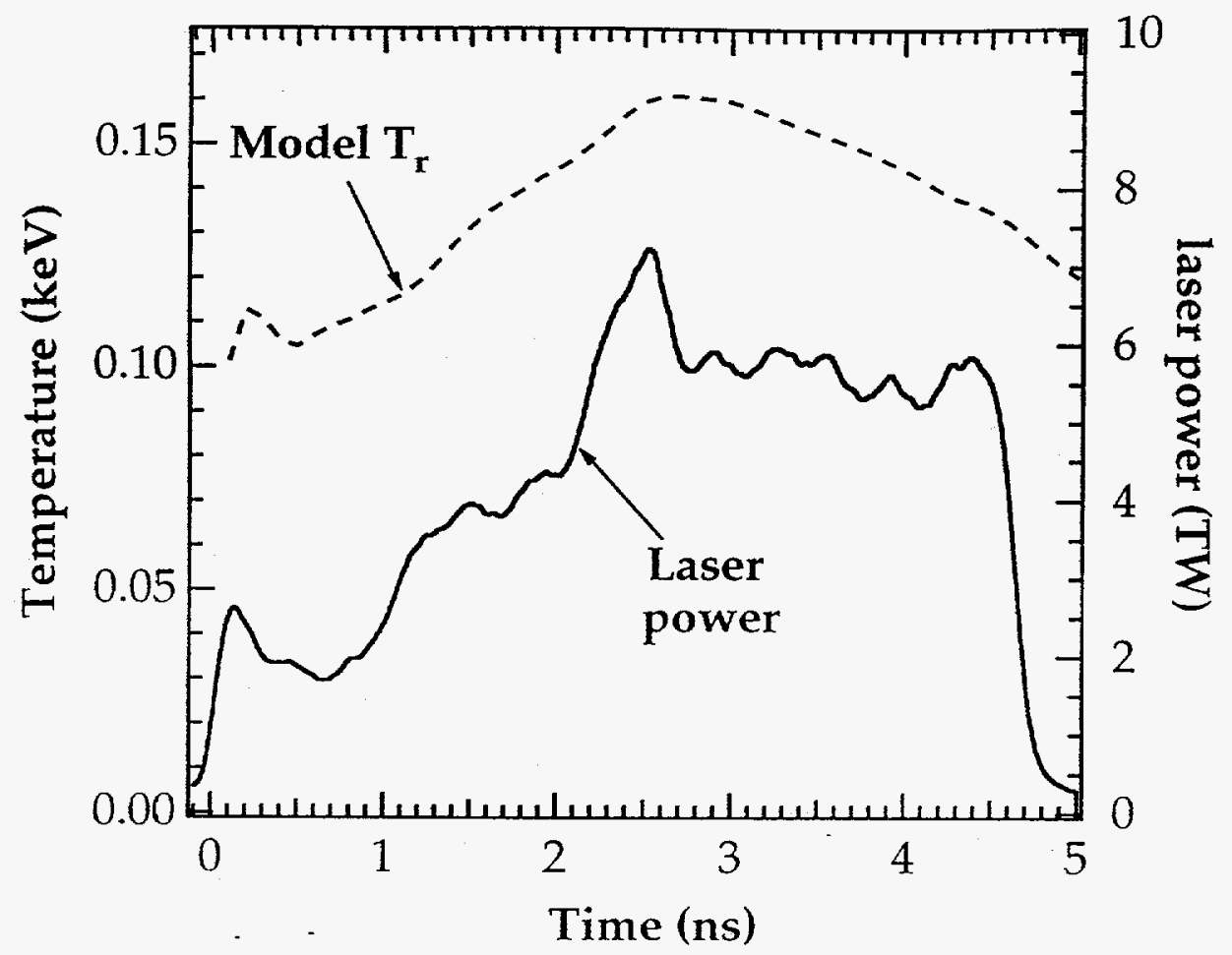

b.

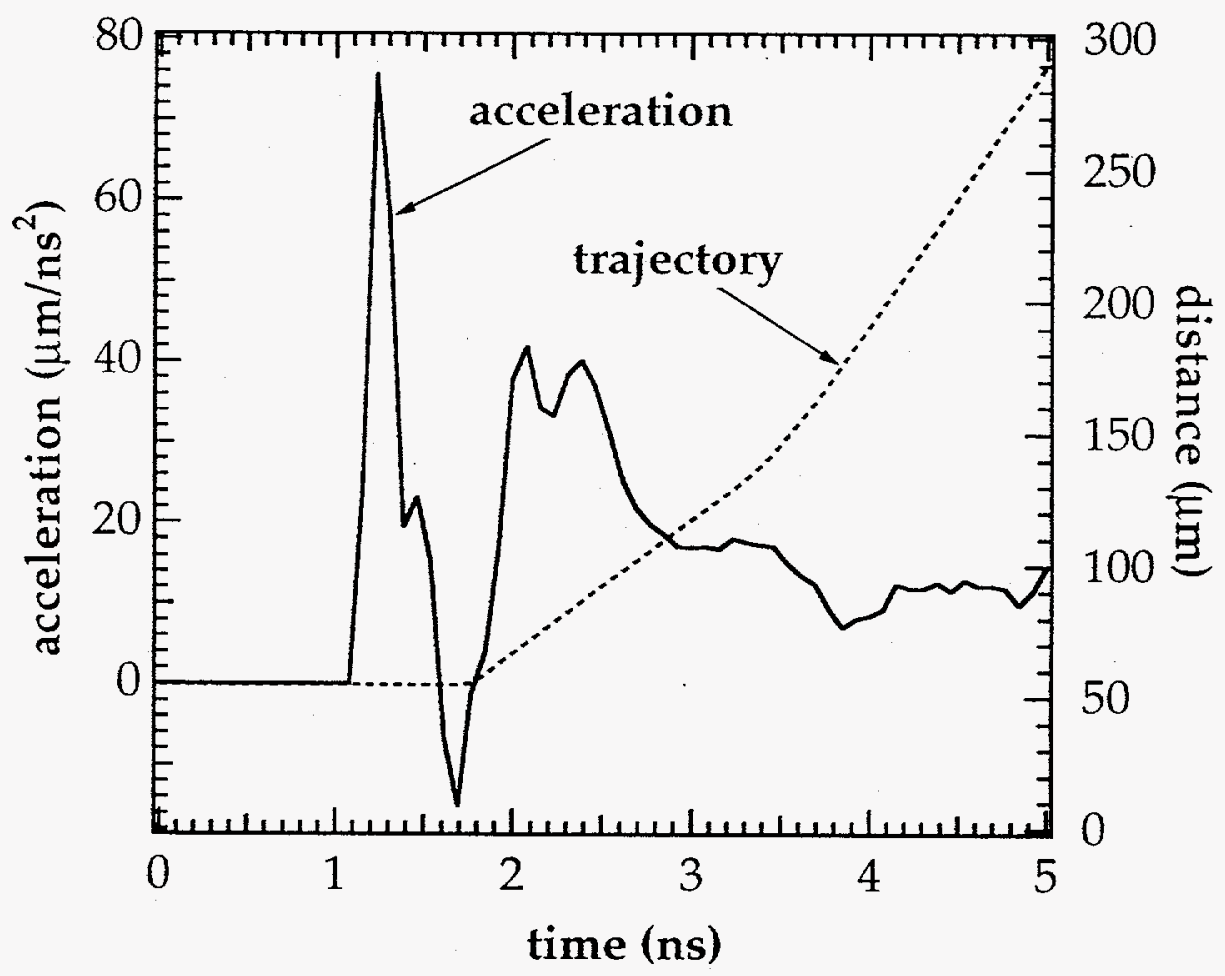

Figure 3 


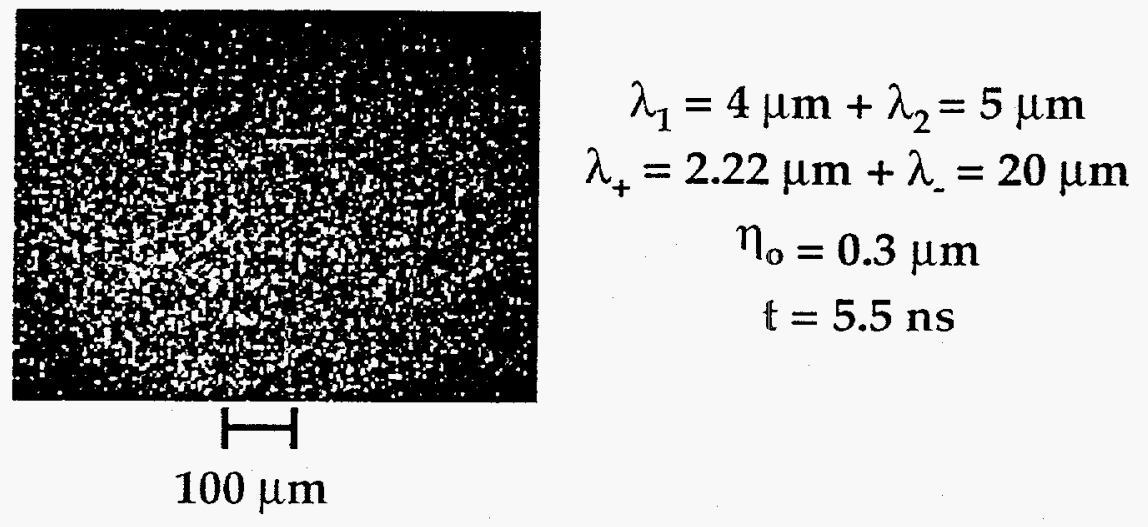

Figure 4 
a.

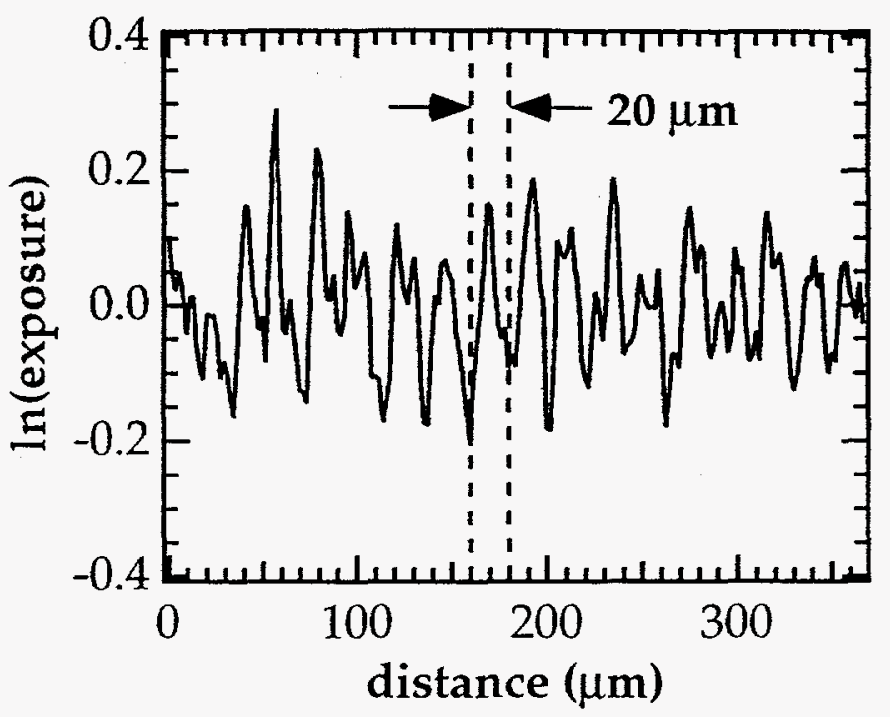

b.

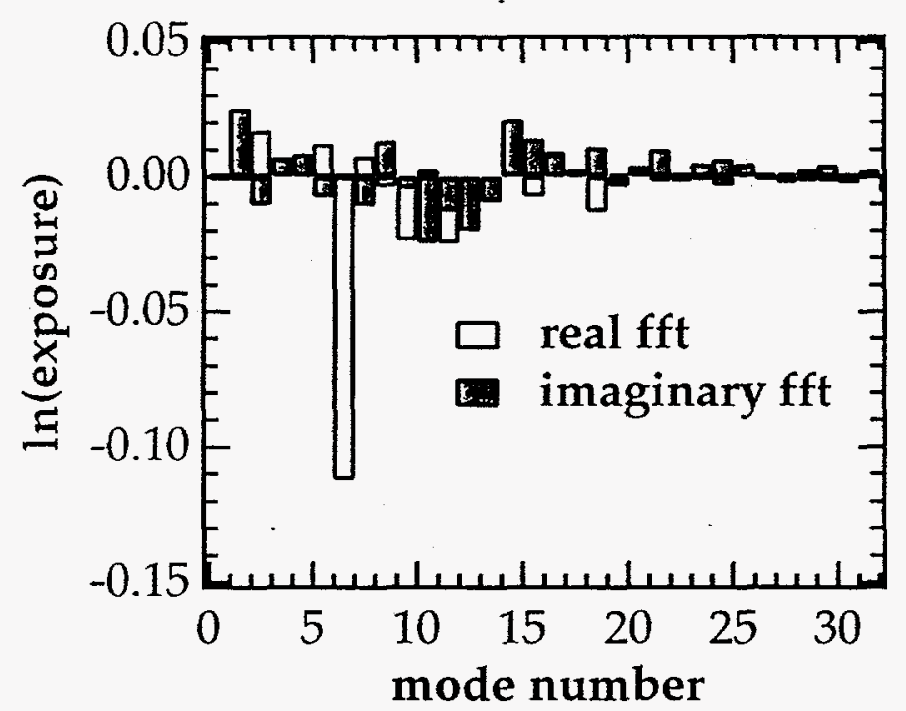

Figure 5 


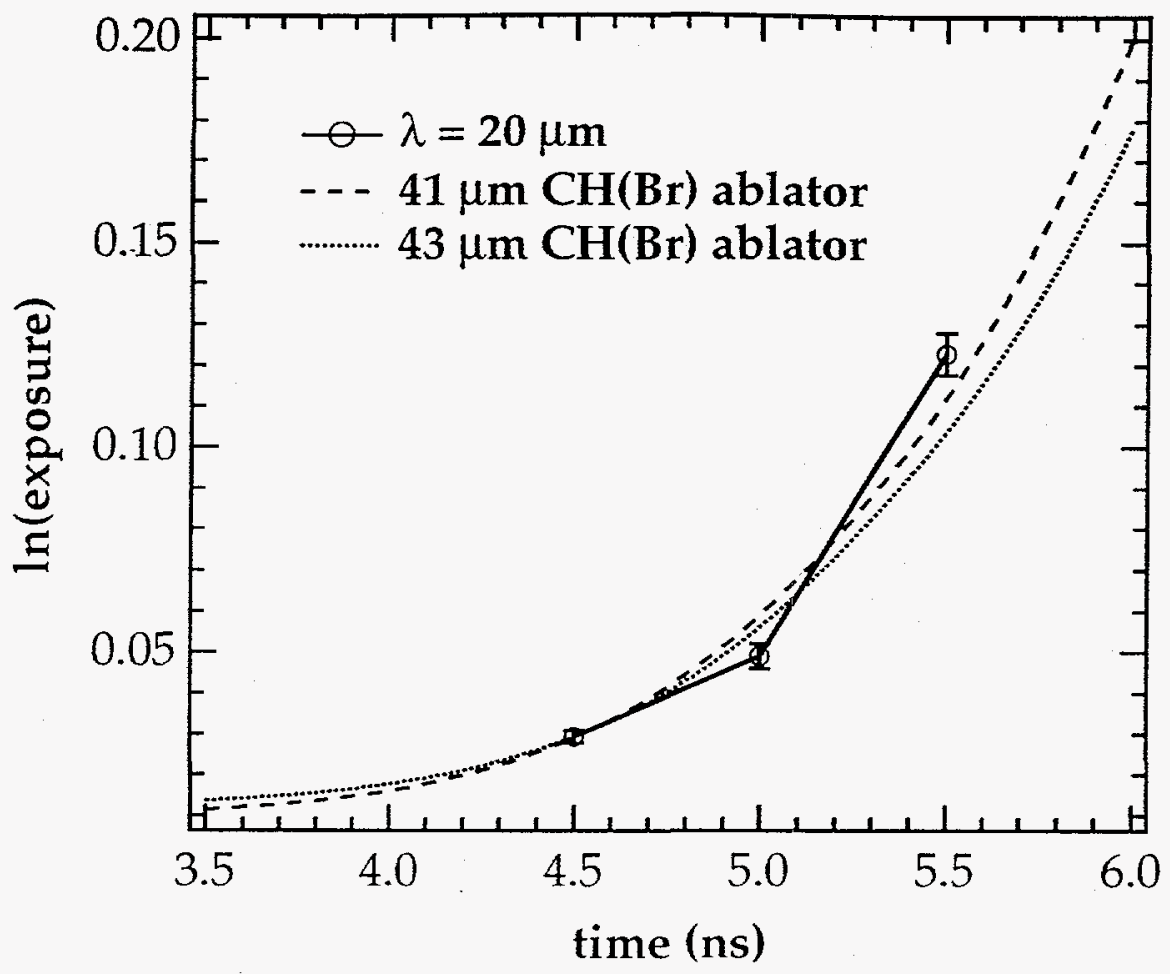

Figure 6 